\title{
A hydrological simulation of the water regime in two playa lakes located in southern Spain
}

\author{
Rodriguez-Rodriguez Miguel ${ }^{1, *}$ and Schilling Malte $^{2}$ \\ ${ }^{1}$ University Pablo de Olavide, Seville, Spain. \\ ${ }^{2}$ Carl Von Ossietzy University, Oldemburg, Germany. \\ ${ }^{*}$ Corresponding author.e-mail: mrodrod@upo.es
}

The subject of this paper is the detailed hydrological simulation of two playa lakes located in southern Spain from January 2011 to March 2012 on a daily basis. These playas are placed over a 400-km² shallow aquifer, which is exposed to an increasing stress caused by agricultural activities, mainly olive grove plantations. The objective of the paper is to elaborate a detailed numeric model that simulates the water regime of each playa lake on a daily scale. The simulation is compared to measured water level (WL) data of the playas in order to characterize the groundwater-surface interactions. The ultimate objective of this paper is to assess the environmental impact of the increasing anthropogenic water consumption within the area of research. The results of the GW-surface interaction were very consistent with previous works. One of the playa lakes is groundwater-dependent and the other one is presumably a perched playa lake. The GW discharge of the former playa $(214 \mathrm{~mm})$ during the research period stands in sharp contrast to no regional GW discharge in the latter. Water level data prove that the hydrological year (2011-2012) had a very negative water budget. The evapotranspiration estimation was almost as high as double the sum of the precipitation, the runoff, and the groundwater discharge. The simulation of an anthropologically altered water regime proves that water retrieval has a harmful impact on the WL of the playa lakes as well as on the aquifer.

\section{Introduction}

Andalusia, the southernmost region of Spain, is characterized by its hot and semi-arid climate. Hydrologically sensitive areas such as the shallow aquifer Osuna-La Lantejuela (O-LL) are strongly affected by two facts: seasonal change of the meteorological conditions and changes in the use of land, as it has been stated by several authors in the recent past (Rodríguez-Rodríguez et al. 2007; Beltran et al. 2012). Due to the high evaporation rates, a brine dominated by $\mathrm{Na}$ and $\mathrm{Cl}$ develops in the groundwater where the lakes are placed. The high evaporation concentrates the playa lakes' water and, by means of diffusion, groundwater salinity is higher in the zones of the aquifer where the playas are located. Therefore, these systems are interpreted as the end-members of local groundwater flow lines moving slowly towards the center of each endorheic basin. Consequently, the playas are local discharge areas of the aquifer, although some of them receive groundwater from the regional aquifer, whilst other playas only receive subsurface and surface run-off from their respective watersheds, this depending on the precise location of the playa lake and the permeability of the materials on such location (Rodríguez-Rodríguez et al. 2007). Beltran et al. (2012) found that the materials forming the aquifer had an overall extension of $919 \mathrm{~km}^{2}$ of which $431 \mathrm{~km}^{2}$ consist of permeable

Keywords. Hydrology; modelling; wetlands; irrigation 
outcrops. The playa lakes are located in the north of the basin area of the aquifer and are partially groundwater-dependent. The vegetation tolerates high salinity concentrations in the soil water and responds very sensitively to alterations of the respective water regime of the playas.

The objectives of this paper are:

- The elaboration of a detailed hydrological model by means of a water budget. The water budget aims to quantify the direct precipitation and evaporation of the playa lake as well as the run-off and GW discharge and recharge. Here, GW discharge is defined as GW that flows from the aquifer to the playa and GW recharge is defined as infiltration from the playa to the aquifer.

- The definition of the surface-groundwater relationship of the two unaltered playa lakes Ballestera (henceforth 'Ball') and Calderón (henceforth 'Cald').

- The simulation of an altered water regime caused by an increased anthropogenic GW consumption within the watershed area of Ball playa-lake.

\section{The area of research}

The study area is located in the depression of the river Guadalquivir (see figure 1). Very soft slopes and relatively low altitudes, except of the southeastern part, characterize the site. The altitude ranges from 110 to $604 \mathrm{~m}$ above sea level. For this reason, a subcontinental Mediterranean climate dominated by hot summers predominates. The annual mean temperature, using data from 1969 to 2006 , averages $17.8^{\circ} \mathrm{C}$ (Moral et al. 2008). The mean temperature of August is $27.4^{\circ} \mathrm{C}$ (http://sig. magrama.es/siga) and that of January is $10.0^{\circ} \mathrm{C}$. The average annual precipitation from 1969 to 2006 was $496 \mathrm{~mm}$, although the total rainfall varies extremely from year to year. Moreover, the rains are spread over the year very unevenly. During June, July and August, a very marginal amount of the annual rain occurs, and between December and February a high percentage of the precipitation is measured. Moreover, in September very torrential rains that represent a major part of the total rainfall occur occasionally.

Due to the high mean temperature, the potential annual evapotranspiration $\left(E T_{0}\right)$ averages $956 \mathrm{~mm}$ (Beltran et al. 2012). The evapotranspiration has an annual distribution that is very similar to the evolution of the temperature. It peaks in July (177 $\mathrm{mm}$ ) and reaches its lowest value in January (20 $\mathrm{mm}$ ). Using the historic data from 1969 to 2006, an annual average run-off of $66 \mathrm{~mm}$ was calculated in the area of research. The water surplus of the soil occurred from January to March peaking with $30.8 \mathrm{~mm}$ (47\%) in February (Moral et al. 2008).

The agricultural use of the land affects the water surplus of the soil feeding the playa lakes and the aquifer. As the lakes underlay a constant seasonal change and represent a very dynamic biotope, a very small change may have a considerable impact. Only the two analyzed playa lakes in the area have a relatively natural hydrological regime. Anthropologically altered conditions in the other seven playa-lakes prevail. The water of their catchment areas is exploited, affluent streams are regulated or limestone crust originating from the surrounding fields is dumped in the lake. For this reason, it is crucial to include the agricultural use of the area of research in order to understand its impact on the change in storage in the lakes. As figure 1 depicts, the land use has changed considerably in the last few decades. In comparison to the former agricultural use the area of irrigated land increased by 9.6 ha and represents $18.3 \%$ of the total area of the administrative district of Osuna. This is mainly due to the increasing irrigation of olive plantations. This plant consumes a relatively low amount of water (Castro et al. 1999). Nevertheless, a farspread increase of this plantation may affect the water regime.

The wetland complex consists of nine playa lakes that are located in the administrative district of Osuna in the east of the village La Lantejuela. The municipal district belongs to the region of Seville. The wetlands are situated in a plane with soft slopes (less than 10\%). None of their catchment areas exceed a steepness of $2 \%$. The area has a relatively low altitude between 145 (level of playa lakes) to $175 \mathrm{~m}$ a.s.l. (surrounding elevations). The stream Salado de Osuna flows between Cald and Ball lakes (see figure 1) and is an ephemeral water course that dries up in summer. This water course was channelized in the first half of the 20th century in order to avoid flooding. Most of the playa lakes are currently drained, and this anthropogenic interference leads to a profound transformation of the playa lakes except for the playa lakes Cald and Ball that are in a protected zone. Their morphological characteristics can be observed in table 1. The O-LL aquifer consists of a detrital unconfined hydrogeological system made up by Plio-Quaternary alluvial materials (Moral et al. 2008; Rodríguez-Rodríguez et al. 2008). The thickness in the northern part ranges from 4 to $8 \mathrm{~m}$ and increases considerably southwards, where it reaches a maximum thickness of $40 \mathrm{~m}$. The material's flow properties are very heterogeneous. Precipitation, GW discharge, and sporadic flooding of the rivers (this phenomenon does not occur in the analyzed playa lakes) contribute positively to the aquifer's change in storage. Evapotranspiration, 

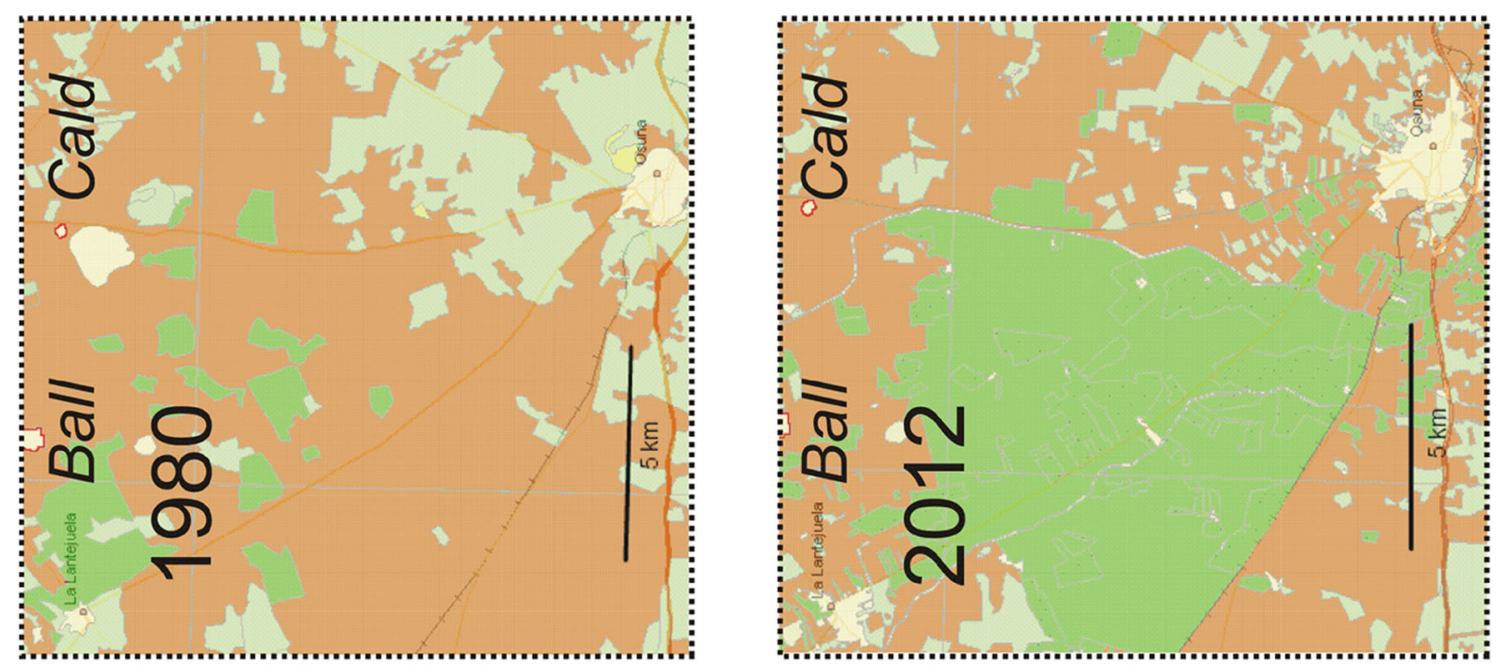

ก
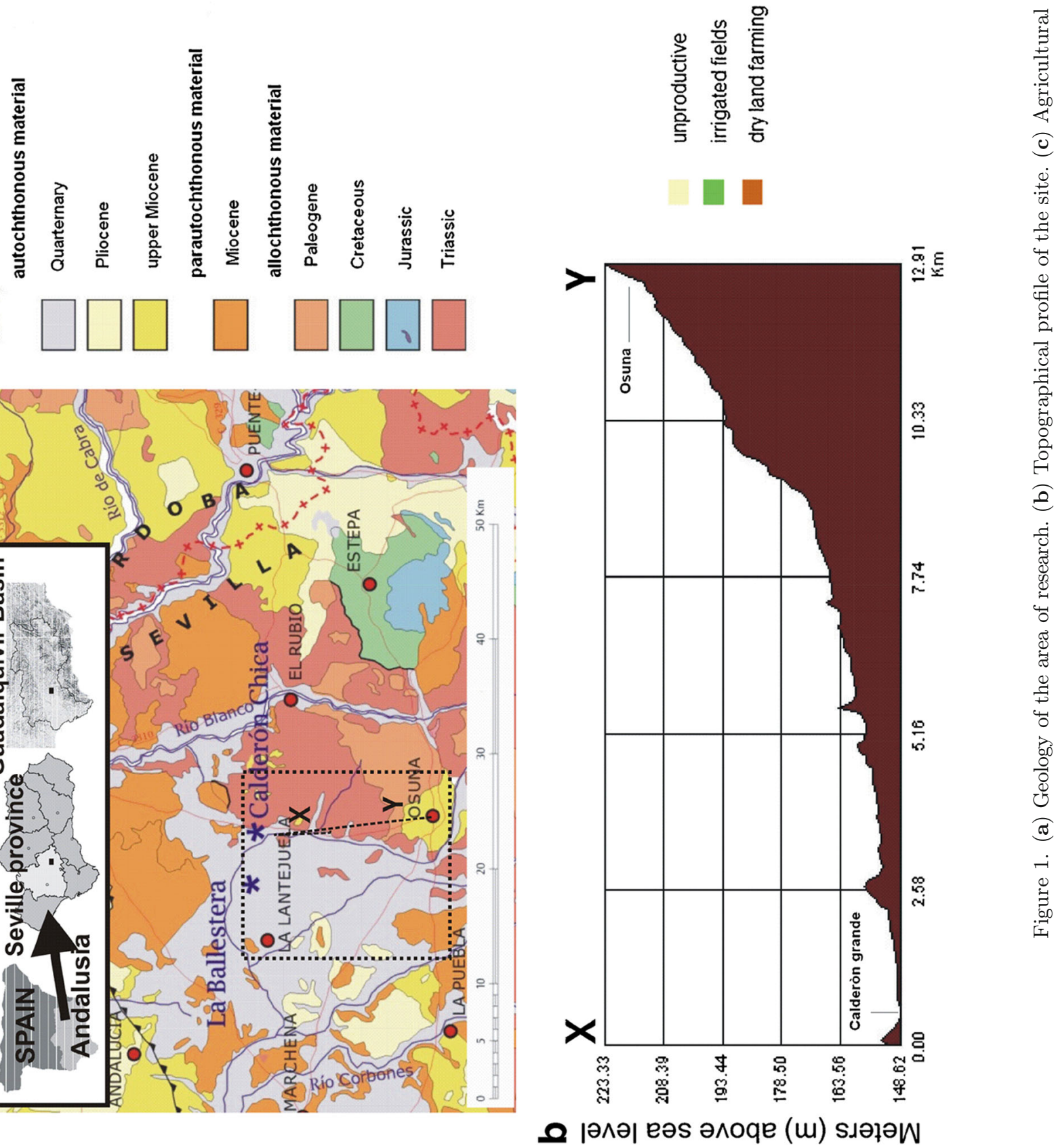

$\mathbf{0}$

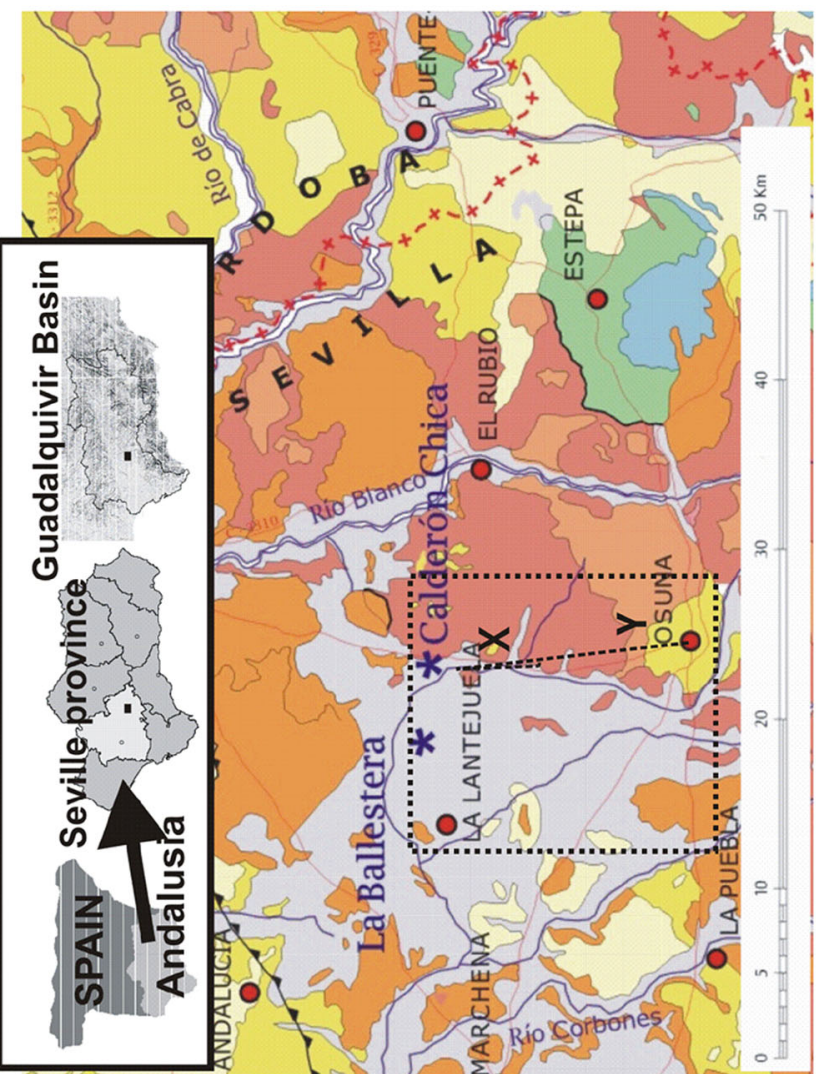


Table 1. General data describing the playa lakes' morphometry.

\begin{tabular}{lrcrc}
\hline & W & Altitude & AFS & W/AFS \\
\hline Cald & 63.3 & 148.67 & 5.9 & 10.7 \\
Ball & 102.9 & 144.75 & 26.1 & 3.9 \\
\hline
\end{tabular}

W: watershed (hectares); Altitude (m above sea level); AFS: Average flooding surface (hectares). The area/flooding surface ratio of Cald leads to the conclusion that it is perched. According to the ratio, Ball seems to be a groundwaterdependent playa lake.

the discharge to the rivers, GW recharge, and water withdrawal are negative components of the water budget. The GW level is close to the surface $(3-4 \mathrm{~m})$, and the regional flow path of the GW has a component of $\mathrm{N} 330^{\circ} \mathrm{E}$, meaning that water flows from the elevations around Osuna to the northeast towards the playa lakes, that are local discharge areas of the aquifer. The impermeable layer underneath the aquifer consists mainly of Triassic clay and evaporites.

\section{Materials and methods}

\subsection{Change in water storage of the playa lakes}

The hydrological balance of the playa lakes is the change of its water volume over time $(\Delta V / \Delta t)$. This change depends on various factors, meaning that every recharge and discharge needs to be taken into consideration. The detailed equation showing that the change in the water storage of a playa lake depends on various components of the hydrological cycle can be expressed as:

$$
\Delta V / \Delta t=P-E+S i+G i-S_{0}-G o
$$

$P$ stands for the direct precipitation on the playa lake. The total volume of precipitation comes from the multiplication of the current surface of the playa lakes in $\mathrm{m}^{2}$ by the amount of the precipitation in $\mathrm{m}$, at each time interval 1 day).

$E$ is direct evaporation from the lake's surface. The potential evapotranspiration $\left(E T_{0}\right)$ estimated by means of Penman's equation (Penman 1948) equals the actual total evaporation, given that an infinite amount of water is available. This assumption is made for the playa lakes, so the total volume of actual evaporation from the playa lakes is the multiplication of the surface of the playa lake that day $\left(\mathrm{m}^{2}\right)$ by the amount of evaporated water $(\mathrm{m})$. During the study period, which has been very humid, the lakes had not dried up. In the same sense, the effects of salinity in evaporation fluxes are important when the specific gravity of the brine is 1.3 or more (Oroud 1995). In this case, this effect had been considered negligible because the specific gravity of the water of the playas was 1.02 in both playas (measured on 05/12/2012).
$S i$ is the run-off, which is the water surplus (in $\mathrm{m}$ ) of the soil of the basin exceeding the given water holding capacity (WHC) of that soil. Si (runoff) was calculated by means of the computation of a daily soil water budget. The soil water budget can be used to obtain actual evapotranspiration $(E T)$ and run-off $(S i)$ for a given dataset of $P$ and $E T_{0}$ and for a given WHC (Jensen et al. 1990). The surplus is the fraction of precipitation that exceeds the $E T_{0}$ and is not stored in the soil. For the purposes of this study, $E T_{0}$ was calculated using the Thornthwaite method (Thornthwaite and Mather 1955) and the Penman method, as explained above. The simple model used here does not distinguish between surface and subsurface run-off, therefore, includes both. This dataset was calculated daily by using the potential evaporation, precipitation, and WHC of the soil and then multiplied by the surface of the basin minus the surface of the playa lake that day $\left(\mathrm{m}^{2}\right)$.

$S_{0}$ is the surface outflow of the playa lake. This value is set equal to zero because there is no outflow to a river.

Go is the GW recharge of the playa lake. GW recharge should not be a very important component of the water budget of the lake on an annual scale, due to the low permeability of the materials and the fact that the playas constitute local discharge areas (Rodríguez-Rodríguez et al. 2008). In summer, the formation of a salt crust over the playa's bottom indicates that there should be little infiltration from the lake to the aquifer (i.e., less GW recharge). In addition, the evolution of the water level in periods without run-off is very similar between observed and measured. This gives us confidence in the method of estimation of the water output (direct evaporation $=$ Penman $E T_{0}$ ) and no GW recharge.

$G i$ is the GW discharge to the playa lake, i.e., regional groundwater flows coming onto the playa lake. It has to be taken into account that the hydrogeological terms 'recharge' and 'discharge' are always referred to the aquifer, so recharge is always infiltration of water to the aquifers and discharge is always from the aquifer to elsewhere, that is, a lake, a river, a spring, or the sea. The calculation of the discharge is made assuming that also less discharge should be expected from the aquifer to the lake. If the expected WL is different from the calculated WL and the previous assumption taken into account, GW discharge is estimated by the residual from the above given equation. If there is a GW discharge to the playa lake $(G i)$ the measured WL values would be always higher than the theoretical ones. In order to quantify the GW recharge and discharge $(G o / G i)$ a model excluding those values is set up and compared with the WL values. The difference between both plots equals 
the volume of the flow. Therefore, the total discharge would be the sum of the difference of the increments of the measured and the theoretical volume value (including $P, E T_{0}$ and $S i$ ).

Although the materials of the area in the basin are of low permeability (clays and marls), coarse and very permeable material is deposited at the playa lake bottom, which is the lowest part of the watershed area. Therefore, a relatively thin aquifer below the flooding surface is formed. This hydrological context determines the parameters that are included in the model. The precipitation, the runoff, and the possible GW discharge, as well as the evaporation, are considered.

In order to characterize a playa lake's interaction with the GW, Beltran et al. (2012) postulated that the watershed area/flooding surface ratio is very conclusive. Playa lakes with a ratio of approximately 10, match to the model excluding the GW discharge of the aquifer. This model describes an isolated and perched playa lake.

If the value is lower, i.e., the watershed area is closer to flooding surface, the bottom substratum should be permeable, and a GW interaction is expected.

If the value ranges from 10 to 15 , a GW output is probable (artificial or natural). This ratio can lead to very good conclusions, even though other factors such as the bottom substratum should be analyzed as well in order to draw correct conclusions.

\subsection{Data acquisition for the water balance}

The selected meteorological station is located 15 $\mathrm{km}$ in the south of the playa lake Cald on the western outskirts of the town Osuna. In order to avoid any errors caused by the urban microclimate, the instruments are geared to the west. The station's coordinates are $37^{\circ} 15^{\prime} 22^{\prime \prime} \mathrm{N}$ and $05^{\circ} 08^{\prime} 01^{\prime \prime} \mathrm{W}$ and it is situated $255 \mathrm{~m}$ asl on one of the southeastern elevations of the investigation site and, therefore, approximately $70 \mathrm{~m}$ higher than the playa lakes. The regional council (Junta de Andalucía) refers to the station with the number 11 and the ministry of environment with the code 5998A and the name Osuna 'S.E.A.' The data, covering 426 days between 20/01/2011 and 20/03/2012, has been retrieved from the Council of Andalusia, Ministry of Agriculture and Fishing, 2012. The dataset include the daily mean temperature, the atmospheric pressure, the potential evapotranspiration using the Penman method, and the precipitation. The weather station has operated since 1967, and the data covering the entire period were used to obtain the average values of the precipitation and temperature. Daily automatic data are available since year 2000.

\subsection{Water level data}

A Diver ${ }^{\circledR}$ sensor was installed in both playa lakes, attached to the lake's scale, in order to measure the WL of the respective wetlands. The actual WL of each playa lake was calculated using WL data. The obtained data is the pressure, which is proportional to the water depth plus the atmospheric pressure. The subtraction of the barometric data, obtained from a BaroDiver ${ }^{\circledR}$ installed between Cald and Ball playas, equals the relative WL of each playa lake. The absolute WL needs to be defined by linking one particular WL value to a measured water gauge. On October 13th 2011 at 11 am the depth of Ball was $0.50 \mathrm{~m}$ and that of Cald was $0.71 \mathrm{~m}$ (Rodriguez-Rodriguez et al. 2011). The WL data are adjusted accordingly, so that absolute WLs of the period of research match the real value.

In relation to the surface and volume of the playa lakes, the hypsographic curve (depth-surface) of the playas can be observed in table 2 . The depthvolume relationship is also shown in table 2 .

Previous investigations revealed that the Cald playa lake is perched and that its water regime is very simple (Rodríguez-Rodríguez 2008). The only water inputs are direct precipitation and the runoff. The only water output is the evaporation. As the precipitation and evaporation are known, the run-off is the only unknown variable of the model, so the entire model has only one incognita. Comparing the simulated WL values with the actual WL values in the playa retrieved from the sensors, the WHC can be found iteratively. It needs to be stated that the computed WHC does not necessarily correlate with real field data, as it is a computed theoretical value. The values depend on the applied time scale and the method used to measure the evaporation with Thornthwaite (Thornthwaite and Mather 1955) or Penman methods (Penman 1948).

The Diver ${ }^{\circledR}$ piezometer was used to obtain WL data of the playa lakes. The measurement was carried out in 3 -hr interval. Eight values covering one entire day were averaged in order to obtain the daily WL. The program Trasero ${ }^{\circledR}$ (Padilla et al. 2005) was used to calculate the potential evapotranspiration from the soil with the Thornthwaite method, the effective or actual evapotranspiration from the soil with both the Penman and Thornthwaite method and the run-off at a daily scale.

\section{Some remarks concerning the calibration of the water budget model}

As commented above, 'recharge' and 'discharge' are always referred to the aquifer, so recharge is 
Table 2. Water depth-surface and water depth-volume relationship (from Rodriguez-Rodriguez et al. 2011).

\begin{tabular}{lcc}
\hline Playa lake & Depth-surface relation & Correlation $R^{2}$ \\
\hline Ball & $\mathrm{a}=147280^{*}($ depth $/ \mathrm{m})+80979$ & 0.7657 \\
Cald & $\mathrm{a}=44624^{*}($ depth $/ \mathrm{m})-2928$ & 0.9376 \\
& Depth-volume relation & Correlation $R^{2}$ \\
Ball & $V=52.283^{*}(\text { depth } / \mathrm{m})^{2}+142.71^{*}($ depth $/ \mathrm{m})-4.142$ & 0.9992 \\
Cald & $V=23.2^{*}(\text { depth } / \mathrm{m})^{2}-5.0078^{*}(\operatorname{depth} / \mathrm{m})-1.514$ & 0.9981 \\
\hline
\end{tabular}

a: area (in $\mathrm{m}^{2}$ ); depth $/ \mathrm{m}$ : depth in $\mathrm{m}$ : The volume $(V)$ is given in $10^{3} \mathrm{~m}^{3}$. More information and original report http://www.chguadalquivir.es/opencms/portalchg/servicios/ estudiosTecnicos

always infiltration of water to the aquifers and discharge is always a water flow from the aquifer to elsewhere. Once the WHC was calibrated in both playas, we observed that in the case of Cald, the model fits well. In Ball playa, the differences between observed (higher) and modelled (lower) water level are big enough to think that there are other ways of water input towards the playa lake. The rest of the components are correctly estimated, because in Cald playa lake, with similar characteristics, the balance was validated. So the only way to fit the model is considering Gi (GW regional inflow) not equal to zero. We are aware that here is a cumulative error in considering $G i$ as the residual of the equation, but the GW flow expected is coherent with the measurements of permeability and hydrogeology of the O-LL aquifer, and that was stated by the authors in several published papers and reports (Rodríguez-Rodríguez et al. 2007, 2008, 2011; Beltran et al. 2012).

\section{Results}

It is essential to determine the water holding capacity (WHC) in order to quantify the theoretical runoff that matches with the actual WL data. For this reason, theoretical approaches including different WHCs are used and the results are compared to the measured WL data. In figure 2, a comparison between estimated WLs and actual WL can be observed. We used the Penman method to estimate potential evapotranspiration $\left(E T_{0}\right)$ in the basin and, then, the total run-off on a daily scale with different values of the WHC. The model including a WHC of $253 \mathrm{~mm}$ matches best with the actual WL data. It can be assumed that both catchment areas have the same WHC value. With the parameters given, it may be assumed that $1.1 \mathrm{~mm}$ run-off is generated in both catchment areas during the entire period of researching of 426 days. The elaborated models with a WHC inferior to $225 \mathrm{~mm}$ have a considerably higher run-off and therefore a higher water volume than the measured value.

Nonetheless, the mentioned models correlate very well at the beginning of the measuring period, which is the rainy and cold season. This is due to the fact that soils with lower field moisture capacities hold less water, and the run-off is generated relatively quickly. As the rainfalls measured with a daily scale do not occur evenly spread over the day but rather, run-offs may occur very suddenly too. The models with higher WHC smoothen out sudden and torrential rainfalls; thus the volume curve of the playa lake is smoother as well. The fact that the graphs with higher WHC have a delayed response to precipitation proves this assumption.

We also used the Thornthwaite method to estimate potential $E T_{0}$ in the basin and the total run-off with different values of the WHC (see figure 3). The simulated WHC that matches best with the real data is $358 \mathrm{~mm}\left(R^{2}=0.9912\right)$. The resulting value of the WHC is higher than the value obtained with the Penman method, because of the subestimation in the value of the $E T_{0}$ using this methodology (Chen et al. 2005).

In relation to the surface-groundwater relation of the playa lakes, and to both visualize and quantify the hypothetical discharge of the aquifer into the playa lake (Gi) two datasets are used. The first one is the measured dataset. The second is the model extensively discussed in the previous sections, which excludes only the GW discharge. Therefore, the difference between both datasets is the GW discharge (Gi) onto the playas.

The graph of Ball depicts an obvious GW discharge (table 3) because the measured WL at the end of the research period was $0.42 \mathrm{~m}$ higher than the simulated one. In contrast to Ball, the hydrodynamic conditions of Cald are unclear. The substratum lithology consists of marls and of a thin layer of quaternary sediments. The playa lake is situated at the edge of the Triassic materials, with a lower permeability. Furthermore, the aquifer's WL 

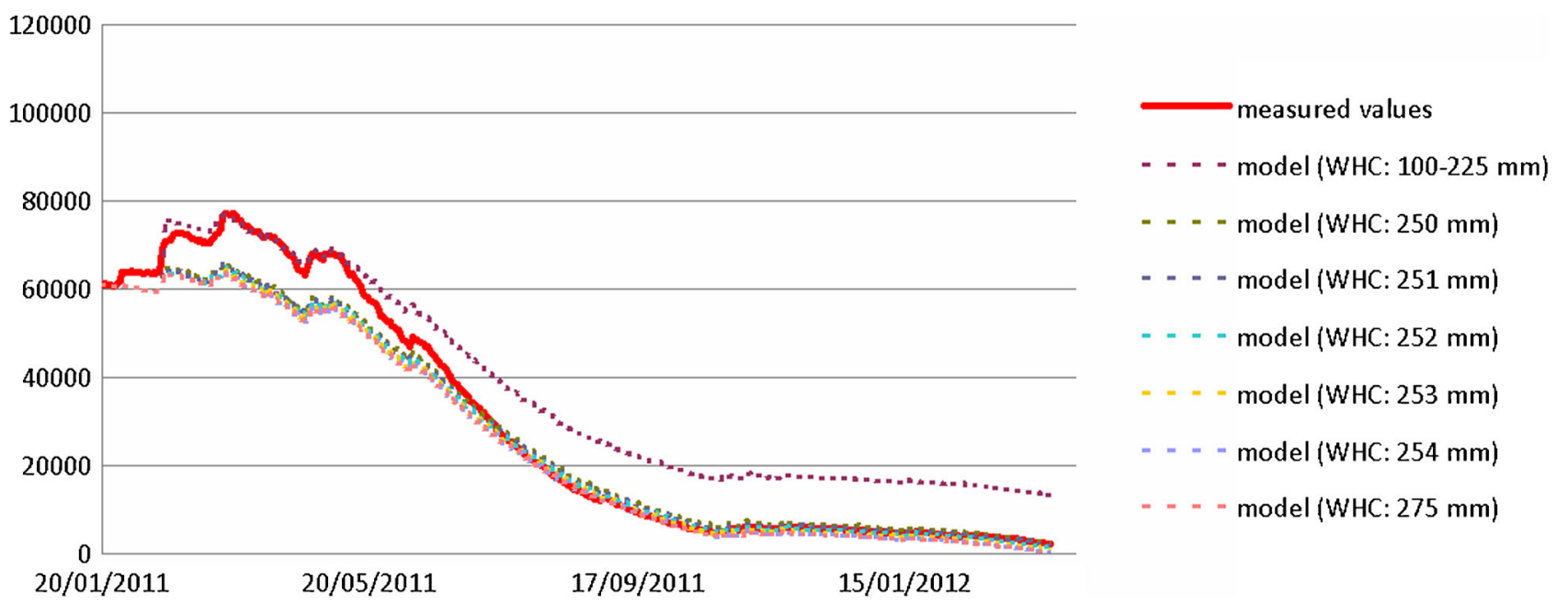

- - - model (WHC: $250 \mathrm{~mm}$ )

- - - model (WHC: $251 \mathrm{~mm}$ )

- - - model (WHC: $252 \mathrm{~mm}$ )

model (WHC: $253 \mathrm{~mm}$ )

- - - model (WHC: $254 \mathrm{~mm}$ )

- - - model (WHC: $275 \mathrm{~mm}$ )

Figure 2. Comparison of the measured water volume in Cald $\left(\mathrm{m}^{3}\right)$ and results of the models with differing water holding capacities (WHC). The total run-off was computed using the Penman method to estimate the $E T_{0}$ in the watershed.

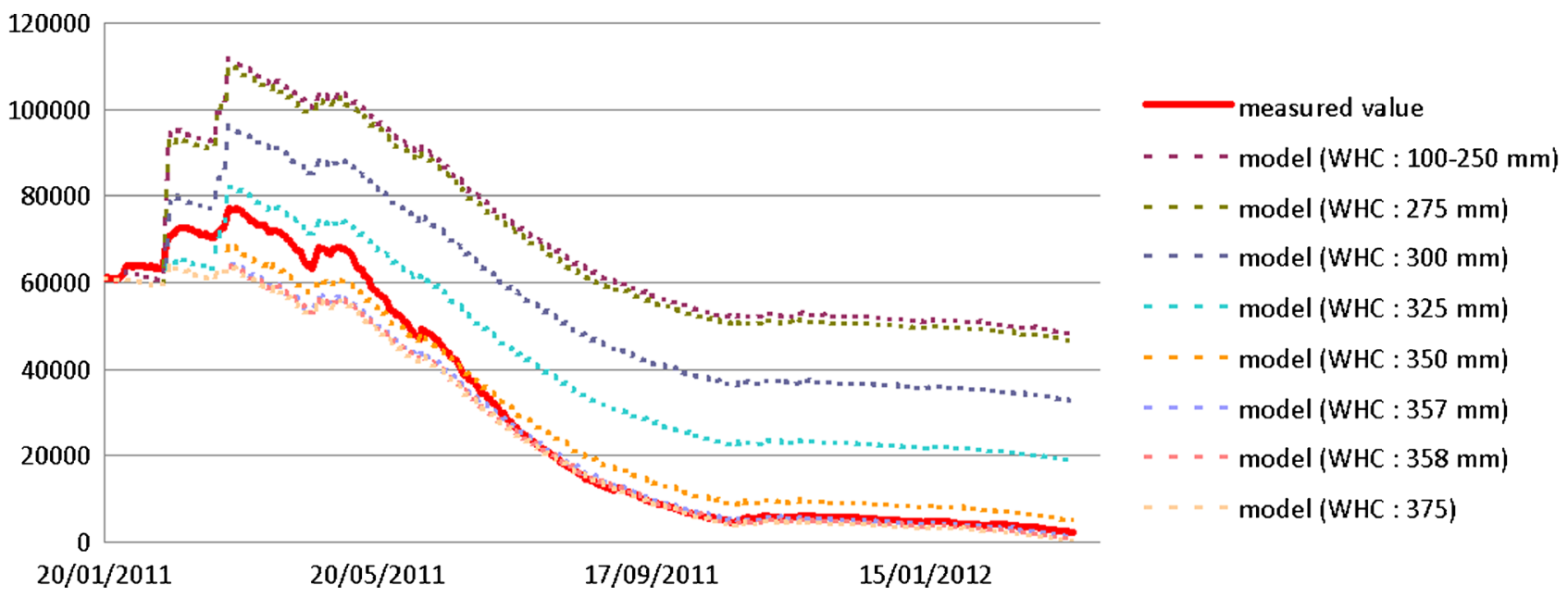

Figure 3. Comparison of the measured water volume in Cald $\left(\mathrm{m}^{3}\right)$ and results of the models with differing water holding capacities (WHC). The total run-off was computed using the Thornthwaite method to estimate the $E T_{0}$ in the watershed.

Table 3. Hypothetical $G W$ discharge of the aquifer onto the lake.

\begin{tabular}{llccr}
\hline $\begin{array}{l}\text { Playa } \\
\text { lake }\end{array}$ & \multicolumn{1}{c}{$\begin{array}{c}\text { Bottom } \\
\text { substratum }\end{array}$} & $\begin{array}{c}\text { Total discharge } \\
\left(\mathrm{m}^{3}\right)\end{array}$ & $\begin{array}{c}\text { Daily discharge } \\
\left(\mathrm{m}^{3}\right)\end{array}$ & $\begin{array}{c}\text { Discharge } \\
(G i) / \mathrm{mm}\end{array}$ \\
\hline Cald & Marls, quaternary sediments & 1369 & 3.2 & 25.4 \\
Ball & Fluvio-lacustrine deposits & 67766 & 159.1 & 214.3 \\
\hline
\end{tabular}

Note: The component of total discharge in Cald playa has been estimated as $50 \%$ of the total run-off of the soil water budget.

is $7 \mathrm{~m}$ below the surface. Therefore, the presumption that there is a GW discharge has to be called in question.

In relation to the water budget's components, the direct evaporation of the playa lake plays the biggest role in the water budget. It is more than four times higher than the direct precipitation or GW discharge. Both precipitation and the discharge of Ball, as positive water budget components, are half as much as the evaporation $(50.2 \%)$. The run-off is marginal $(0.001 \%$ of the evaporation) thus it does not equalize the positive and negative water budget components. This is due to the fact that the effective evaporation of the watershed area is double the local precipitation (202.2\%). Thus, barely any run-off is generated. 


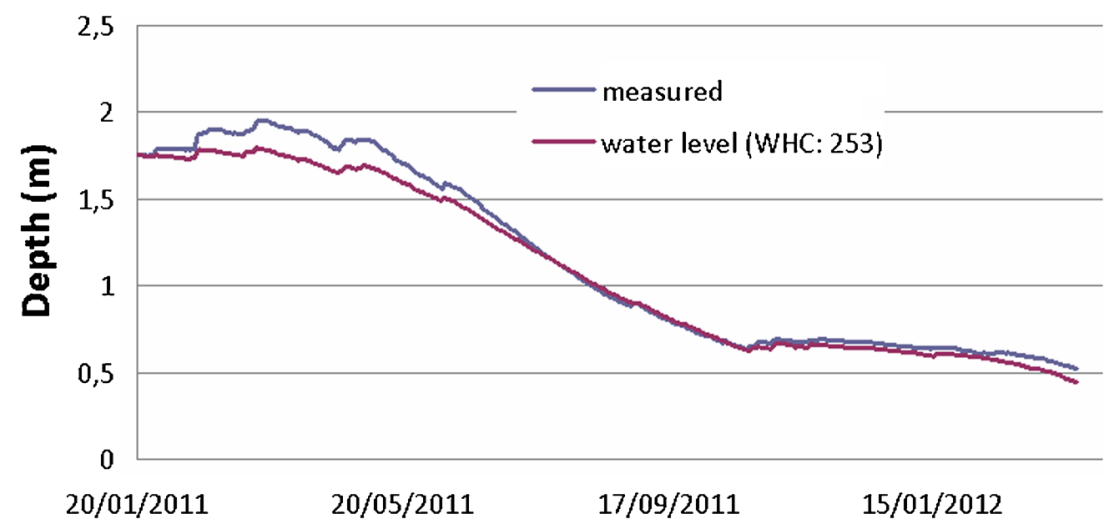

Figure 4. Result from the calibrated model and the measured water level data of Cald. The evaporation from the playa was calculated with the Penman method (for both direct and $E T_{0}$ in the watershed).

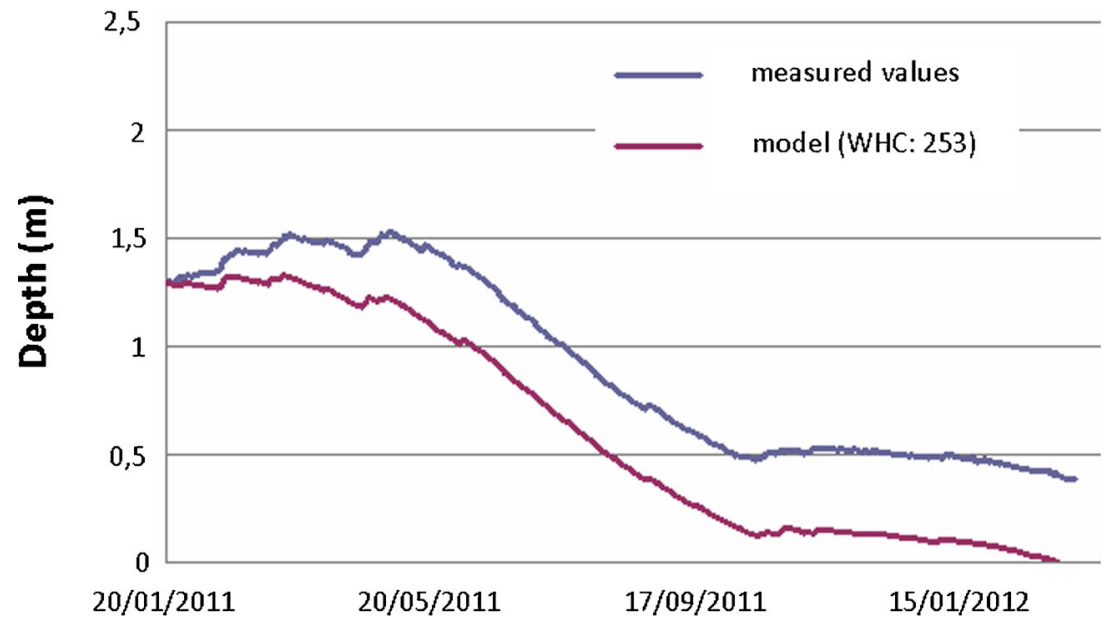

Figure 5. Differences between the calibrated model (excluding the GW exchange) and the measured water level of Ball. The evaporation used for the model was exclusively calculated with the Penman method.

The water budget of Ball is negative. The precipitation, the run-off, and the GW discharge equals $826 \mathrm{~mm}$ and the evaporation $1643 \mathrm{~mm}$.

The water budget of Cald is even more out of balance as no (or very little) GW discharge occurs. The positive water budget components $(P$, Si) are equal to $385 \mathrm{~mm}$ and the negative ones (evaporation) to $1643 \mathrm{~mm}$.

The extremely negative water budget is visualized in figures 4 and 5 . The figures show the measured WL of the playa lakes during the research period. Judging by the WL, the hydrological year 2010/2011 was very wet and the last year (2011/2012) very dry. During the rainy season of the $2011 / 2012$, only a relatively small increase of the level can be observed in contrast to the previous season. The WL on January 20 (2011) in Cald playa lake is $1.11 \mathrm{~m}$ lower than on January 20 (2012). The WL of Ball decreased 0.79 $\mathrm{m}$ in one year. As already mentioned in the previous section, the research period was very dry and the decrease of the WL considerable. In order to provide a better overview of the meteorological conditions of the area of research, data covering a longer period of time was studied. The precipitation measured between January 20, 2011 and March 20, 2012 was $384.2 \mathrm{~mm}$. The period covers 8 months of the hydrological year 2010/2011 and 6 months of the year 2011/2012 (426 days in total, see figure 6 ). The amount of precipitation during hydrological years 2009/2010 and winter 2010/2011 was unusually high. That is why the initial WL of the playa lakes was so high at beginning of the study and decreased drastically during the period of research.

As it was stated previously, the area of research is increasingly exploited for agricultural use. The maximum irrigation of a field, which is regulated by the Ministry of Agriculture in Spain, is 7000 $\mathrm{m}^{3} / \mathrm{ha} /$ year. The ideal yearly amount of water for a productive olive plantation is $1500 \mathrm{~m}^{3} /$ ha/year (Castro et al. 1999). This value is used for the simulation, as olive plantation constitutes the main crop of the area of research. Furthermore, it is a 


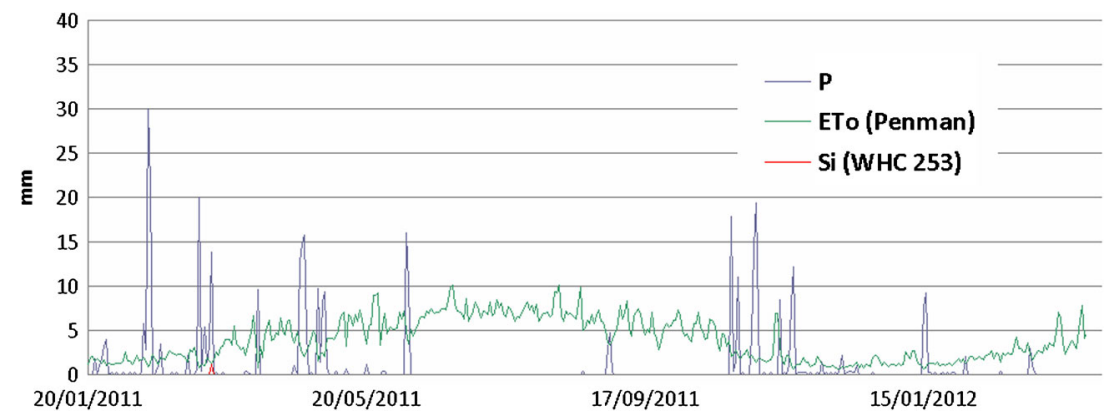

Figure 6. Relationship between the meteorological conditions and the run-off of the catchments areas. Only one run-off event was calculated on March 14, 2012. The Penman method was used in this model to calculate the evaporation of the playa lake and evapotranspiration from the watershed area.

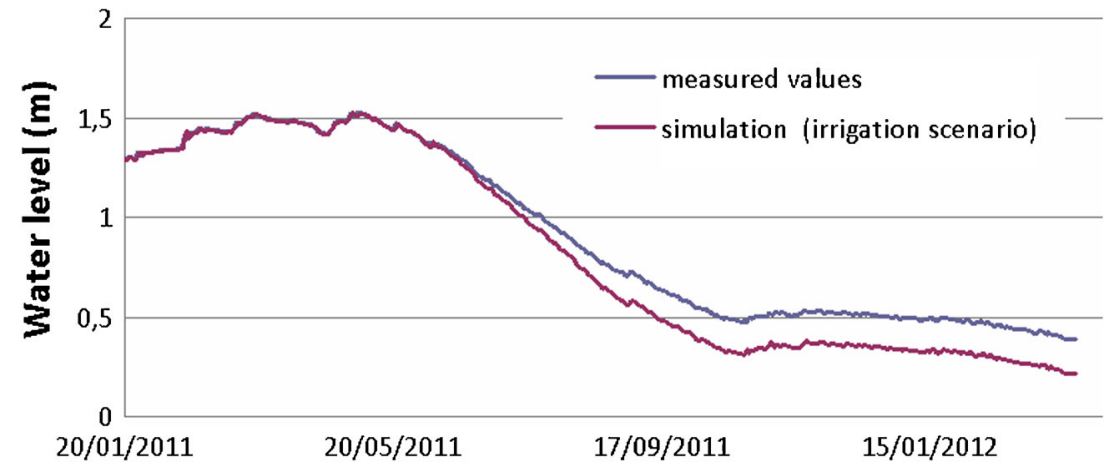

Figure 7. The water level of Ball, if $100 \%$ of the catchment area is used for olive plantation. The simulated water level is a complete model including $P, E r, S i, G i$ and the artificial water pumping.

well-known fact that irrigation is only needed in hot summer months. Therefore a water withdrawal in June, July and August was assumed (3 months). The duration of irrigation is three months and takes place in June, July and August. If the geological conditions of the bottom of Cald and the marginal run-off are taken in account, the playa lake should be only in a small degree affected by the groundwater withdrawal of the permeable materials of the O-LL aquifer (as can be deduced from the cross section in figure 8). Therefore only Ball is subject of the simulation.

If the entire catchment area were used for drip irrigation from drillings, with a groundwater demand - taken from the O-LL aquifer - for olive grove plantations of $1500 \mathrm{~m}^{3} / \mathrm{ha} /$ year, this would have resulted in a water consumption of $30 \times 10^{3} \mathrm{~m}^{3}$ over the 426 days of the study. The resulting WL would have been $20 \mathrm{~cm}$ lower than the actual WL in the lake within this scenario (figure 7).

\section{Discussion}

Several case studies were done in order to get a better understanding of the endorheic system of Osuna-La Lantejuela (Rodríguez-Rodríguez et al. 2008; Beltran et al. 2012). The objectives of the last work (Beltran et al. 2012) were a better hydrological understanding of the endorheic system and a quantification of each hydrometeorological variable. Furthermore, a conceptual model, which simulates the water regime, was elaborated in order to facilitate predictions of hypothetical changes. In addition, several studies have been published recently in which the same water balance method has been applied to similar Andalusian playa-lakes at different time scales (Rodríguez-Rodríguez et al. 2011; Moral et al. 2013). In such studies, the definition of the conceptual model for a low-land playa has been established and the results of the modeling has shown that regional (i.e., coming from outside the hydrological watershed) groundwater flow will be expected to discharge to the playa lakes only if the ratio (watershed area/flooding surface) is, in general, less than 6 .

In the case of La Lantejuela playa-lakes, the hydrogeomorphological conditions of the playas determine their relationship with the aquifer. The bottom substratum of the Ball playa lake is detrital quaternary sediment and the Cald playa lake is located on quaternary as well as Triassic material. Moreover, the comparison of the flooding 

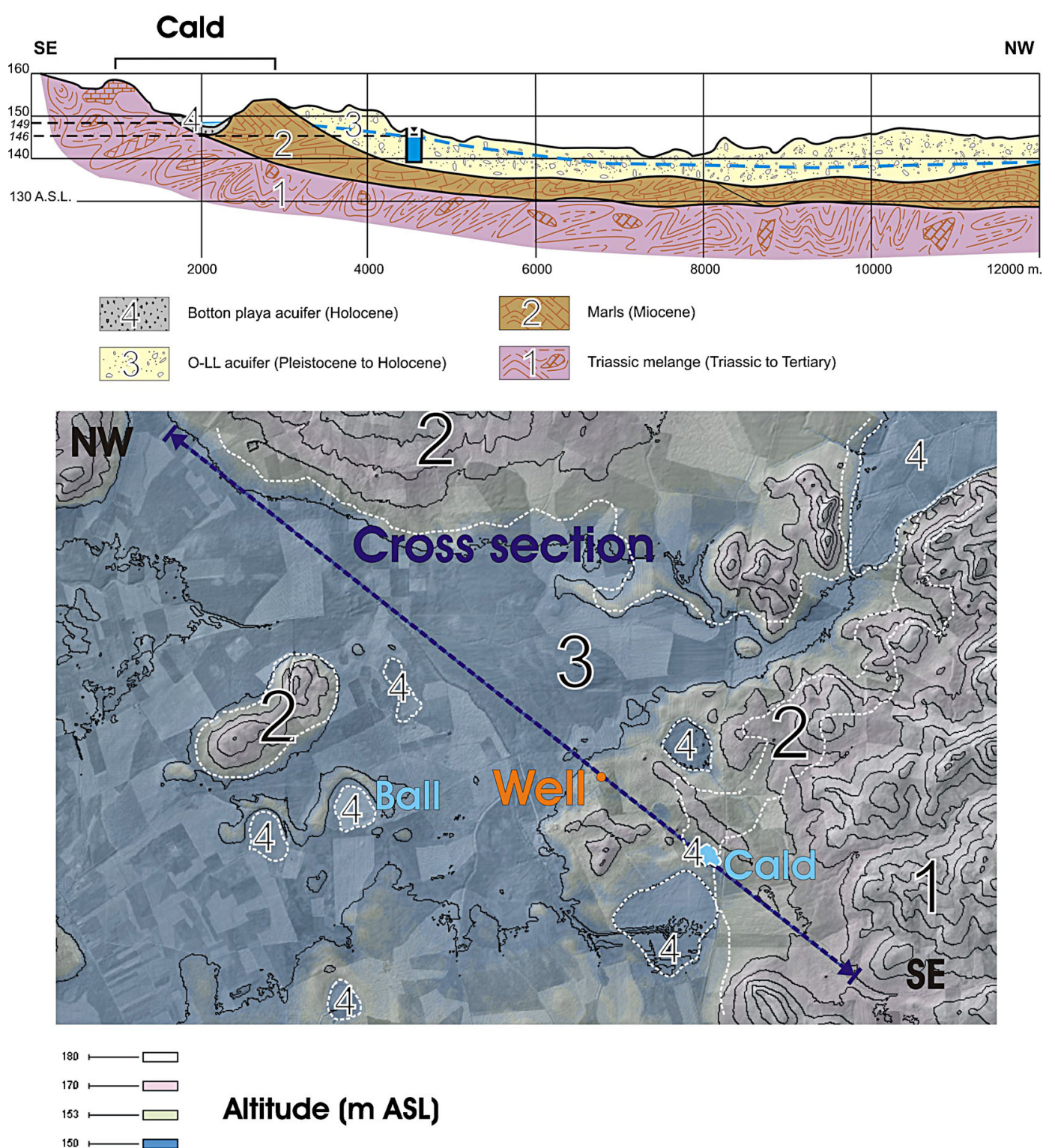

Figure 8. Above: NW-SE hydrogeological cross-section of the study area, showing the relative position of Cald playa lake to the O-LL aquifer. Below: Altitude map showing the cross-section, as well as the position of the main playas of the study area and lithological contacts.

surface (5.9 ha Cald and 26.1 ha Ball) with the watershed area (Cald 63.3 ha, Ball 102.9 ha) is a very conclusive ratio that allows determining of the surface-GW interaction. Applying the characterization of the playa lakes based on the mentioned ratio, Beltran et al. (2012) concluded that the Ball playa lake is connected to the aquifer and that the hydraulic conditions of Cald are different, as it is a perched system, disconnected from the permeable rocks that form the O-LL aquifer, as it can be viewed in figure 8 . This conclusion was confirmed by the latest data. The present data show a maximum WL of $1.95 \mathrm{~m}$ on March 16/2011 and at no time the playa lake ran dry. The data show that the playa lake reached an extreme high WL and confirmed its high variability caused by meteorological heterogeneity. Rodriguez-Rodriguez et al. (2008) concluded that there is a discharge of the aquifer of Ball and thus confirms the statements referring to the GW exchange made in this work. Nonetheless systematic piezometric information and detailed geochemical investigation is needed to confirm this hypothesis.

\section{Conclusions}

The elaboration of a hydrological model by means of a water budget was carried out in two playa lakes, Ball and Cald, situated in O-LL aquifer.

For the estimation of the run-off, two models have been employed using different methods to 
calculate soil evapotranspiration (Penman and Thornthwaite). In addition, different values for the WHC have been used to calibrate the model. The computed WHC of the soil highly depends on the applied time scale and the used method to calculate the potential. Judging from the data of the period of research the playa lakes may be characterized as follows:

- The assumption that the Ball playa lake is connected to the aquifer was confirmed.

- The GW interaction of Cald is negligible or nonexistent.

The relationship between the meteorology and the water regime is given in the following:

- The direct evaporation of the playa lakes during the present period of research was considerably higher than the direct precipitation, the run-off, and the GW discharge.

- The run-off is highly dependent on the current meteorological conditions, so it varies considerably.

- The WL of the playa lakes underlies a seasonal as well as a yearly change, which is due to the high variability of the meteorological parameters. In the year 2011, the precipitation was below average.

The impact of an anthropogenic alteration of the water regime is summarized in the following:

- An anthropogenic alteration of the water regime by means of groundwater retrieval from the O-LL aquifer constitutes a great impact on the WL of Ball. The wetland may run dry earlier in summer, reducing the natural hydroperiod. The level of the respective aquifer might be also lowered significantly, as a function of the level of GW withdrawal for irrigation in the area. Finally, the reserves of O-LL aquifer are low, because of the shallowness of the permeable deposits. So, the intense exploitation of GW in the system would lead to a fast exhaustion of the water resources both in quality and quantity.

\section{Acknowledgements}

This work has been carried out in the framework of an academic exchange between the Carl von Ossietzky University Oldenburg and Pablo de Olavide University Seville. The collaboration was established, thanks to the close contact of G Massmann (Carl von Ossietzky University Oldenburg) and
C Kohlfahl (Spanish Geological Survey). Authors would like to thank them for having made this collaboration possible. Furthermore, they would like to thank J M Bruque Carmona, who is staff member of the Pablo de Olavide University for his helpful advices and everlasting patience. They are also grateful to the reviewers whose comments and suggestions have improved both the quality and the explicitness of this research.

\section{References}

Beltran M, Moral F and Rodriguez-Rodriguez M 2012 Changes in the hydrological functioning of a playa-lake complex under increasing agricultural pressures (Andalusia, southern Spain); Water Environ. J. 26 212-223.

Castro J et al. 1999 Respuestas del olivar tradicional a diferentes estrategias y dosis de agua de riego (Response of the traditional olive grove to different strategies and irrigation dosis), Investigación agraria; Producción y protección vegetales 14 393-404.

Chen D, Gao G, Xu C-Y, Guo J and Ren G 2005 Comparison of the Thornthwaite method and pan data with the standard Penman-Monteith estimates of reference evapotranspiration in China; Clim. Res. 28 123-132.

Jensen M E, Burman R D and Allen R G 1990 Evapotranspiration and irrigation water requirements; American Society of Civil Engineers, New York.

Moral F, Rodriguez-Rodríguez M, Beltrán M, Benavente J and Cifuentes V J 2013 Water regime of playa-lakes from southern Spain. Conditioning factors and hydrological modeling; Water Environ. Res. 85(7) 632-642.

Moral F, Rodríguez-Rodríguez M, Benavente J and Beltrán M 2008 Hydrogeological relations of the Llanos de OsunaLa Lantejuela aquifer and the playa-lake complex of La Lantejuela, Guadalquivir River Authoritie, Seville.

Oroud I M 1995 Effects of salinity upon evaporation from pans and shallow lakes near the Dead Sea; Theor. Appl. Climatol. 52 231-240.

Padilla A, Delgado J and Castillo E 2005 Management and processing of hydrological time series; Algibe Consulting, Alicante.

Penman H L 1948 Natural evaporation from open water, bare soil and grass; Proc. Roy. Soc. London 193 120-145.

Rodríguez-Rodríguez M, Moral F and Benavente J 2007 Anthropogenic alterations and hydrological functioning of a semi-arid playa-lake complex and related detritic aquifer (Seville province, Spain); XXXV International Association of Hydrogeologists Congress, Groundwater and Ecosystems, Lisbon, September 2007, pp. 97-98.

Rodríguez-Rodríguez M, Moral F and Benavente J 2008 Hydrogeological characteristics of a groundwater dependant ecosystem (La Lantejuela, Seville, Spain); Water Environ. J. 22 137-147.

Rodriguez-Rodriguez M, Moral F, Bruque J M and Benavente J 2011 Modelización hidrológica en humedales de la Demarcación Hidrográfica del Guadalquivir (Hydrological modelling in wetlands of the Guadalquivir River Basin), Seville.

Thornthwaite C W and Mather J R 1955 The water balance; Drexel Institute of Technology; Publ. Climatol. 8 1-104. 